\title{
CHARACTERIZATION OF PERMANENT DEFORMATION RESISTANCE OF PRECIPITATED CALCIUM CARBONATE MODIFIED ASPHALT MIXTURE
}

\author{
Fereidoon MOGHADAS NEJAD ${ }^{\mathrm{a}}$, Ali Reza AZARHOOSH ${ }^{\mathrm{b}}$, \\ Gholam Hossein HAMEDI ${ }^{\mathrm{c}}$, Mohammad Javad AZARHOOSH ${ }^{\mathrm{d}}$ \\ a, b, cDepartment of Civil \& Environmental Engineering, Amirkabir University of Technology Tehran, Iran \\ ${ }^{b}$ Department of Civil Engineering, University of Guilan, Rasht, Iran \\ ${ }^{d}$ Department of Chemical Engineering, Amirkabir University of Technology Tehran Iran
}

Received 02 Aug 2012; accepted 13 Nov 2012

\begin{abstract}
Rutting in asphalt pavements that appears as an indentation in the longitudinal direction continues to create problems for pavement agencies. This paper presents the results of the laboratory study on rutting susceptibility of asphalt mixtures containing Precipitated Calcium Carbonate (PCC) coated by a thin layer of a polymeric compound. To assess the impact of PCC on rutting properties of HMA, control mixtures (without PCC) and mixtures containing PCC were tested using dynamic creep and indirect tensile stiffness modulus tests. The HMA mixtures containing $0 \%, 5 \%$, $10 \%$, and $15 \%$ of PCC were prepared. In this paper, it is shown that the use of PCC can decrease the rutting potential of asphalt mixes. According to the results obtained in this study; using a 5\% PCC in HMA is acceptable for heavy traffic volume roads especially in tropical regions.
\end{abstract}

Keywords: precipitated calcium carbonate, rutting, stiffness modulus, dynamic creep.

\section{Introduction}

In recent years, along with the increase of heavy traffic volume in roads, the rutting effect has become one of the most important failures, especially in tropical regions. Rutting is referred to longitudinal depressions which are formed by passing vehicles beside their wheel tracks. Ruts are treated as dangerous defects, since they might cause danger for traffic, especially when the pavement is wet. When its depth goes above 5 millimeters, it reserves water and causes hydroplaning potential (Laurinavičius, Oginskas 2006). Rutting could cause an effect called "bleeding" as well, by which the friction between tires of vehicles and the asphalt attenuates and the number of traffic accidents correspondingly increases. Another deleterious influence of the rutting effect is on pavement in which the thickness of the asphalt layer attenuates and fatigue cracking occurs (Bahuguna 2003). The aforementioned reasons introduce the rutting effect as one of the most remarkable failures in asphalt pavement.

Rutting could happen in almost all stages of the pavement's life span. Two main mechanisms exist that cause rutting. First is pavement densification, i.e. the decrease in mass and increase in density. This form of rutting is caused by compaction and gradual jamming of asphalt and its lower layers, which in turn is caused by a constant flow of vehicles passing on the road. Infirmity is chiefly the state of being weak in health or body; article; maybe: In this case, the main cause of rutting formation would be the weakness of lower layers, including subgrade. Such wide ruts $(0.75 \mathrm{~m}$ to $1 \mathrm{~m})$ are shallow and without cracks. The second stage is shear deformation; plastic flow with no change in the volume.

Rutting is caused by lateral movement of asphalt mixtures under shear stress, which is, in turn, caused by the passage of vehicles. Rutting is mainly caused by weakness in shear strength of asphalt in this case. In this form of rutting, the materials of asphalt mixture are moved laterally and cause depression in loading area. In this case, bumps form beside wheel tracks (Pardhan 1995).

Asphalt binder is one of main materials in asphalt and works as glue for sticking aggregates together. Tendency towards rutting in asphalt mixtures is very much affected by stiffness and the amount of asphalt binder. Several researches have proved asphalt binder's role in rutting effect. With an increase of asphalt binder's stiffness, we can observe an increase in the stiffness of asphalt mixtures and, as a result, in strength against rutting.

However, with the increased traffic volumes and vehicle loads, there is a need to improve conventional asphalt binder properties, particularly its resistance to permanent deformation of the pavement in the form of ruts or corrugations (rutting).

Corresponding author: Fereidoon Moghadas Nejad

E-mail:moghadas@aut.ac.ir 


\section{Literature review}

To date, few studies concerning the use of different modifiers especially polymer asphalt mixtures have been conducted.

Different modifiers have been used to improve the mechanical properties of asphalt binder for many years. In this study PCC coated by a thin layer of a polymeric compound has been employed to modify the performance behavior of asphalt binder in asphalt mixture.

In a study conducted by Kebritchi et al. (2011), the rheological behavior and properties of bitumen modified with polymeric coated precipitated calcium carbonate were described. The obtained results showed that use of modifier leads to increase in rutting resistance which was indicated by stiffness factor. Fourier Transform Infra Red studies emphasized the interaction between modifier and asphalt binder. Scanning Electron Microscopy showed no agglomeration of modifier in the mixtures. Meanwhile, the results showed good storage stability for the modified asphalt binder.

Radziszewski (2007) assessed the modified asphalt mixtures resistance to permanent deformations. This study presents rut and dynamic creep test results of concrete, SMA (Stone Mastic Asphalt), MNU (thin courses of non-continuous grain mixtures), Superpave mixture and porous asphalt mixture of two air void content percentages: $15 \%$ and $20 \%$. Asphalt concrete mixtures, MNU's and porous asphalt mixtures contain elastomer, plastomer and fine rubber modified asphalt binders. The test results show that resistance to permanent deformations depends on the kind of asphalt mixture and asphalt binder applied. Concrete asphalts with fine rubber modified asphalt binders and concrete asphalts with 7\% polymer modified asphalt binders as well as SMA's and Superpave mixtures with unmodified asphalt binders appeared to be the most resistant to permanent deformations after a long-term laboratory aging.

Bernier et al. (2012) evaluated the results of the laboratory study on rutting susceptibility of polymer-modified asphalt mixtures containing Reclaimed Asphalt Pavement (RAP). Accelerated rutting tests were conducted in the Asphalt Pavement Analyzer (APA) and asphalt binders were evaluated in the Dynamic Shear Rheometer in order to construct dynamic shear modulus $\left(\left|\mathrm{G}^{*}\right|\right)$ master curves and to evaluate their viscoelastic and recovery properties using the Multi-Stress Creep Recovery Test (MSCR). The effect of RAP asphalt binder on the APA and MSCR results showed reasonable correlation with reduced rutting for less-modified asphalt binders. Highly-modified asphalt binders were the least affected. Aggregate properties of RAP mix had a noticeable effect on rutting results and adding RAP asphalt binder to the mix lead to reduced rutting.

Jeong et al. (2011) found that the use of waste polyethylene film (WPE film) in asphalt mixtures can improve the performance properties of the mixtures. Asphalt mixtures with two commercial polymer modifiers, low-den- sity polyethylene (LDPE) and a styrene-butadiene-styrene (SBS), were used to compare the effectiveness of the WPE-modified mixture. The strength characteristics such as Marshall Stability and Indirect Tensile Strength (ITS) were evaluated, and the wheel tracking test, the result of which is generally considered to reflect the field performance, was conducted to measure the rutting resistance of the asphalt mixtures. From the results of this study, the asphalt mixture with WPE showed much better rutting resistance than the normal asphalt mixture without WPE. It is hypothesized that if an optimum content of WPE is used, it will be as effective as a commercial modifier in improving the performance of asphalt pavements.

Ozen (2011) evaluated the permanent deformation for hydrated lime and SBS modified asphalt mixtures. Control (C), 2\% hydrated lime (2L), 5\% SBS polymer mixtures and $2 \%$ hydrated lime $-5 \%$ SBS (2L5SBS) mixtures were prepared. The Laboratories Central des Pontset Chaussées (LCPC) wheel tracker was realized. LCPC wheel-tracking test results showed that 2L5SBS mixtures reveal the utmost performance according to the other mixture types. Polymer modification increased the rutting resistance of lime modified ones. Both original LCPC compactor and field cylinder compaction showed similar results. $150 \mathrm{~mm}$ samples showed the highest correlation (higher than $\mathrm{R}^{2}=0.80$ ) between the LCPC test and repeated creep test for different compaction types and different moisture conditionings.

Kumar and Veeraragavan (2011) compared the dynamic mechanical behavior of asphalt concrete mixes with the SBS polymer and crumb rubber modified asphalt binders with the behavior of mixes with unmodified viscosity grade asphalt binders. Simple performance tests such as the dynamic modulus and dynamic and static creep tests are carried out at varying temperatures and time. From the dynamic mechanical characterization studies, it is found that asphalt concrete mixes with a SBS polymer modified asphalt binder showed significantly higher values of dynamic modulus and a reduced rate of deformation at higher temperatures when compared to asphalt concrete mixes with crumb rubber and unmodified asphalt binders.

Khodaii and Mehrara (2009) in a similar study found that $5 \%$ of SBS polymer had better effect on improvement of permanent deformation resistance than $4 \%$ and $6 \%$. Also the mathematical models of creep curves showed that lower stress levels in dynamic creep test cannot show the real behavior of asphalt mixtures and particularly the modified mixtures.

\section{Objective}

The scope of this research was to investigate the rutting of HMA mixtures containing PCC in terms of PCC replacement value and temperature based on the results of dynamic creep and indirect tensile stiffness modulus tests. The rutting behavior of mixtures was compared with each other and the effect of each mixture parameter was investigated. 


\section{Materials}

\subsection{Aggregate and asphalt binder}

In the present study, the granite aggregate was obtained from the Loye mine in Guilan province, Iran. The physical properties of granite are shown in Table 1. An asphalt binder, 60/70-penetration grade obtained from Isfahan Petroleum Refineries was used as the asphalt binder for mixture preparation. The properties of the asphalt binder are presented in Table 2. Also, the gradation of aggregates used in the present study (the median limits of ASTM D3515-01 (2009) specifications for dense aggregate gradation) is shown in Figure 1.

Table 1. Physical properties of the aggregate

\begin{tabular}{lccc}
\hline \multicolumn{1}{c}{ Test } & Standard & Granite & $\begin{array}{c}\text { Specification } \\
\text { limit }\end{array}$ \\
\hline $\begin{array}{l}\text { Specific gravity } \\
\text { (coarse agg.) }\end{array}$ & $\begin{array}{c}\text { ASTM C127-12 } \\
(2012)\end{array}$ & & \\
\hline Bulk & & 2.654 & - \\
\hline SSD & 2.667 & - \\
\hline Apparent & 2.692 & - \\
\hline $\begin{array}{l}\text { Specific gravity } \\
\text { (fine agg.) }\end{array}$ & ASTM C128-12 \\
\hline Bulk & & \\
\hline SSD & & 2.659 & - \\
\hline Apparent & & 2.661 & - \\
\hline $\begin{array}{l}\text { Specific gravity } \\
\text { (filler) }\end{array}$ & $\begin{array}{c}\text { ASTM D854-14 } \\
(2014)\end{array}$ & 2.656 & - \\
\hline $\begin{array}{l}\text { Los Angeles } \\
\text { abrasion (\%) }\end{array}$ & $\begin{array}{c}\text { ASTM C131-06 } \\
(2006)\end{array}$ & 19 & Max 45 \\
\hline $\begin{array}{l}\text { Flat and } \\
\text { elongated } \\
\text { particles (\%) }\end{array}$ & $\begin{array}{c}\text { ASTM D4791-10 } \\
(2010)\end{array}$ & 6.5 & Max 10 \\
\hline $\begin{array}{l}\text { Sodium sulfate } \\
\text { soundness (\%) }\end{array}$ & $\begin{array}{c}\text { ASTM C88-13 } \\
(2013)\end{array}$ & 1.5 & Max 10-20 \\
\hline $\begin{array}{l}\text { Fine aggregate } \\
\text { angularity }\end{array}$ & $\begin{array}{c}\text { ASTM C1252-06 } \\
(2006)\end{array}$ & 56.3 & Min 40 \\
\hline
\end{tabular}

Table 2. Results of the experiments conducted on $60 / 70$ penetration grade asphalt binder

\begin{tabular}{|c|c|c|}
\hline Test & Standard & Result \\
\hline $\begin{array}{l}\text { Penetration }(100 \mathrm{~g}, \\
\left.5 \mathrm{~s}, 25^{\circ} \mathrm{C}\right), 0.1 \mathrm{~mm}\end{array}$ & $\begin{array}{c}\text { ASTM D5-73 } \\
(1978)\end{array}$ & 64 \\
\hline $\begin{array}{l}\text { Penetration }(200 \mathrm{~g}, \\
\left.60 \mathrm{~s}, 4^{\circ} \mathrm{C}\right), 0.1 \mathrm{~mm}\end{array}$ & $\begin{array}{c}\text { ASTM D5-73 } \\
(1978)\end{array}$ & 23 \\
\hline Penetration ratio & $\begin{array}{c}\text { ASTM D5-73 } \\
(1978)\end{array}$ & 0.36 \\
\hline $\begin{array}{l}\text { Ductility }\left(25^{\circ} \mathrm{C},\right. \\
5 \mathrm{~cm} / \mathrm{min}), \mathrm{cm}\end{array}$ & $\begin{array}{c}\text { ASTM D113-07 } \\
\text { (2007) }\end{array}$ & 112 \\
\hline $\begin{array}{l}\text { Solubility in } \\
\text { trichloroethylene, \% }\end{array}$ & $\begin{array}{c}\text { ASTM D2042-09 } \\
\text { (2009) }\end{array}$ & 98.9 \\
\hline Softening point, ${ }^{\circ} \mathrm{C}$ & $\begin{array}{c}\text { ASTM D36-76 } \\
(1976)\end{array}$ & 51 \\
\hline Flash point, ${ }^{\circ} \mathrm{C}$ & $\begin{array}{c}\text { ASTM D92-12b } \\
\text { (2012) }\end{array}$ & 262 \\
\hline Loss of heating, $\%$ & $\begin{array}{l}\text { ASTM D1754/1754M-09 } \\
\text { (2009) }\end{array}$ & 0.75 \\
\hline
\end{tabular}

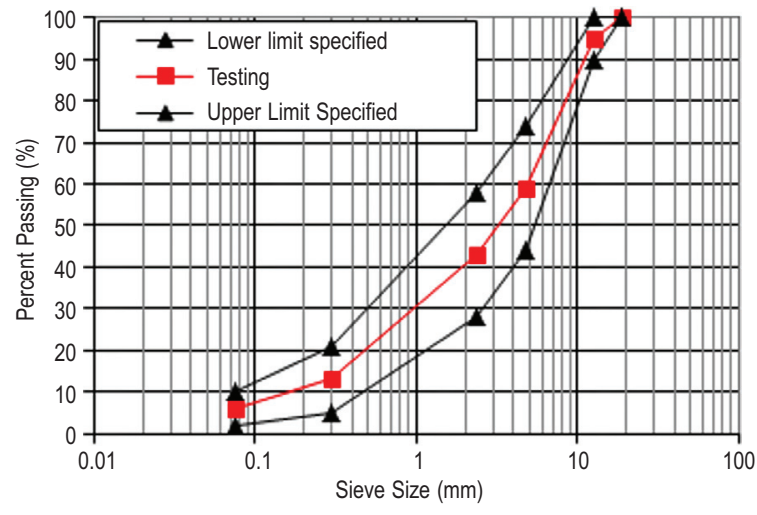

Fig. 1. Grading curves of aggregate

\subsection{Additive}

Precipitated calcium carbonate, with particle sizes between 1 to 40 micro-meters supplied from Iran Barite Company, is used as a modifier in this project. These particles are covered by a veneer of pectin. Pectin is a natural polymer made of the extract of natural materials, such as fruits. The particle size of the used PCC was measured by conducting the particle size distribution (PSD) test method. Figure 2 shows the PSD of PCC.

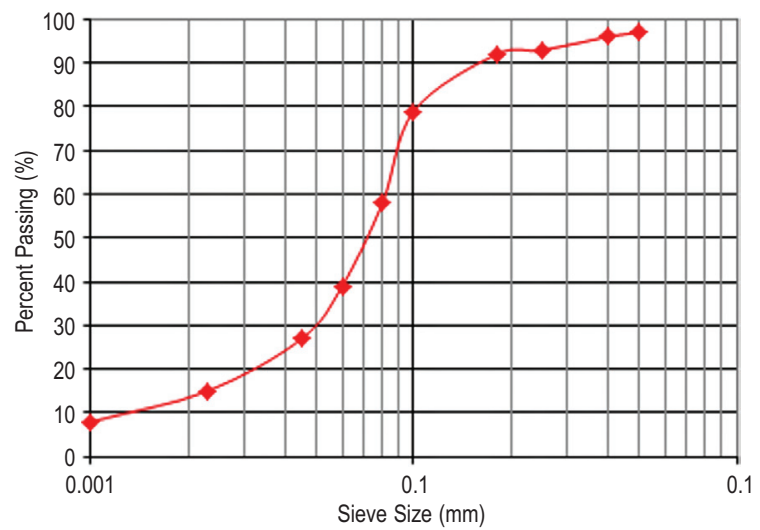

Fig. 2. Cumulative particle size distribution of PCC

\section{Mix design}

Initially, asphalt binder is heated up to $135{ }^{\circ} \mathrm{C}$ and is mixed with different amounts of PCC as shown in Table 3 . The mixing process is carried out using a batch mixer with a speed of $2000 \mathrm{rpm}$ and temperature of $135{ }^{\circ} \mathrm{C}$ for 45 minutes. Samples were cooled after the mixing process and kept to be used for experiments. Results of experiments on pure and modified asphalt binder are illustrated in Table 4.

Table 3. Composition of the prepared bitumen mixtures

\begin{tabular}{lcccc}
\hline Mixture & Control & $\begin{array}{r}5 \% \\
\text { PCC }\end{array}$ & $\begin{array}{r}10 \% \\
\text { PCC }\end{array}$ & $\begin{array}{c}15 \% \\
\text { PCC }\end{array}$ \\
\hline Bitumen $(\%)$ & 100 & 95 & 90 & 85 \\
\hline PCC $(\%)$ & 0 & 5 & 10 & 15 \\
\hline
\end{tabular}


Table 4. Common tests results of PCC modified bitumen

\begin{tabular}{ccccc}
\hline PCC $(\mathrm{wt} \%)$ & 0 & 5 & 10 & 15 \\
\hline Softening point $\left({ }^{\circ} \mathrm{C}\right)$ & 51 & 56 & 56.5 & 59 \\
\hline Penetration $(\mathrm{d} \mathrm{mm})$ & 64 & 51 & 45.5 & 38.5 \\
\hline
\end{tabular}

The Marshal mix design is used for preparing the samples. In the Marshal method, grained aggregates are mixed until 1200 grams of aggregate is reached. These 1200-gram samples are kept at a temperature of $160-170^{\circ} \mathrm{C}$ for 24 hours because the water in the grains should be evaporated. Then, the asphalt binder with a temperature of $135^{\circ} \mathrm{C}$ is mixed with a ratio of

5.5 percent of the asphalt mixture's weight and poured into Marshal molds with sizes of $10.1 \times 6.25 \mathrm{~cm}$. Finally, aggregation is done by 75 strikes of the Marshal hammer, which weighs $4.5 \mathrm{~kg}$ and is released from a height of $45 \mathrm{~cm}$. For each mixture, at least 3 samples are made according to the ASTM-D1074 standard in order to avoid possible errors (ASTM D1074-09 2009).

\section{Experimental setup and procedure}

The tests generally used to assess the resistance of bituminous mixes to permanent deformation are Marshall, static creep, dynamic creep, indirect tensile and wheeltracking tests (Khodaii, Mehrara 2009; Verstraten 1994). In this study, the resistance to permanent deformation of mixtures was evaluated by using the dynamic creep and indirect tensile stiffness modulus tests.

\subsection{Indirect tensile stiffness modulus (ITSM) test}

Stiffness of bituminous material can be measured quickly and easily using the indirect tensile stiffness modulus (ITSM) test under the Nottingham Asphalt Tester (NAT), which is a non-destructive method and has been widely used for the determination of stiffness modulus values (Cooper, Brown1989).

The ITSM test is a non-destructive test, and in this research, it is undertaken in accordance with recognized guidelines (BSI 1993). The stiffness modulus test was performed by applying a linear force along the diameter axis of the specimen. Each loading cycle was $0.1 \mathrm{~s}$ long. Thus, given the total duration of loading and unloading of $1 \mathrm{~s}$, the rest time period of each cycle is $0.9 \mathrm{~s}$ (Arabani, Azarhoosh 2012). Cylindrical specimens with a diameter and height content of $101.6 \mathrm{~mm}$ and $60 \mathrm{~mm}$ were tested, respectively. Three samples for each mix were tested under the diametrical stiffness modulus test at three test temperatures $\left(5,25\right.$ and $\left.40{ }^{\circ} \mathrm{C}\right)$. Eqn (1) shows the stiffness modulus of the samples as determined by the indirect tensile test:

$$
E_{R}=\frac{p(\vartheta+0.27)}{t \times \Delta H},
$$

where: $E_{R}$ is the stiffness modulus, MPa; $p$ the repeated load, $\mathrm{N}$; the Poisson ratio, which is assumed to be 0.35 in HMA; $t$ the thickness of HMA sample, mm; and $\Delta \mathrm{H}$ is the recoverable horizontal deformation, $\mathrm{mm}$.

\subsection{Dynamic creep test}

The dynamic creep experiment has been used for a long time to determine the rutting potential of asphalt, which is due to its simplicity and logical relation with permanent deformation of the asphalt mixture. The main purpose of this experiment is constricted to the classification of materials and their comparison in the area of rutting potential. In other words, we cannot determine the depth of ruts using this experiment. The most important outcome of the dynamic creep experiment is the accumulative strain curve facing the number of loading cycles which depends on compound rutting strength. Figure 3 depicts a form of this curve (Goh, You 2009).

As shown in the figure, the curve is made of 3 major parts: primary zone, in which permanent deformations are quickly accumulated, the secondary zone, in which accumulative strains are increased with a smooth and constant slope, and the tertiary zone, in which the tone of increase in accumulative strain is again increased. The first zone could be identified as a first rutting mechanism (densification; decrease of mass and increase of density). The second zone could be identified as a connector of the two zones. The third zone could be identified as the second rutting mechanism (shear deformation; plastic flow with no change in the volume) (Gokhale et al. 2005).

The dynamic creep test applies a repeated pulsed uniaxial stress on an asphalt specimen and measures the resulting deformations in the same direction using linear variable differential transducers (LVDTs). For the dynamic creep test, cylindrical specimens of $60 \mathrm{~mm} \times 101.6 \mathrm{~mm}$ (thickness $\times$ diameter) were prepared. The dynamic creep test was conducted by applying a dynamic stress of $100 \mathrm{kPa}$ for $1 \mathrm{~h}$ at 5,25 and $40{ }^{\circ} \mathrm{C}$. The tests were performed according to the following procedure. After capping the two sides of the specimen, it was placed in the loading machine under a conditioning stress of $10 \mathrm{kPa}$ for $600 \mathrm{~s}$. Then, the conditioning stress was removed and a stress of $100 \mathrm{kPa}$ was applied for 2000 cycles with $0.1 \mathrm{~s}$ loading and $0.9 \mathrm{~s}$ rest periods, after which the axial deformation was measured during the creep test using LVDTs.

The creep modulus is the most important output of the dynamic creep test. The creep modulus value is an additional indication of the resistance to permanent axial deformation and for bituminous specimens which are ba-

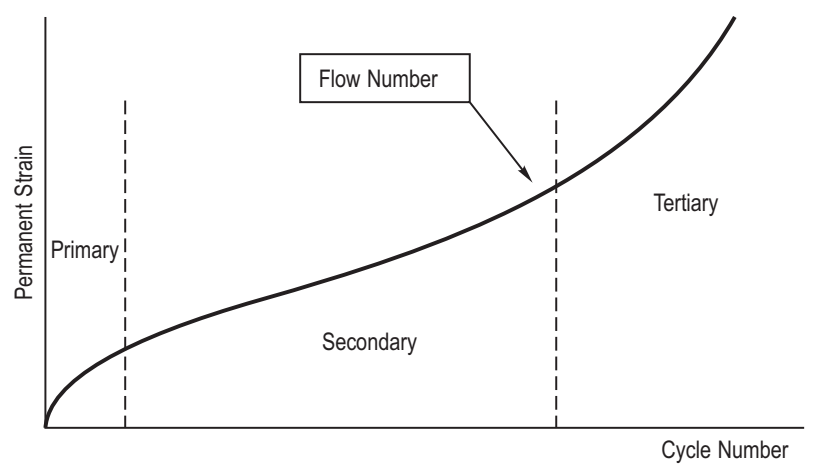

Fig. 3. Typical flow number test result 
sically obtained from the ratio of applied stress $(100 \mathrm{kPa})$ to the cumulative compressive strain at a defined temperature and time of loading. Mixtures with a lower creep modulus are known to undergo higher deformation.

Thus, knowing the initial height of the specimen, the axial strain, $\varepsilon$, and therefore the creep modulus $S_{\text {mix }}$, can be determined at any loading time:

$$
S_{\text {mix }}=\frac{\sigma}{\varepsilon},
$$

where $\sigma$ is the applied stress and $\varepsilon$ is the axial strain.

\section{Results and discussion}

\subsection{Indirect tensile stiffness modulus test}

The stiffness modulus results were determined as shown in Figure 4. The results show that mixtures with PCC have a higher stiffness modulus than the control mixture. Adding PCC to the base asphalt binder results in increases of viscosity, compared with the viscosity of the base asphalt binder. The viscosity of the asphalt binder at high temperatures is considered to be one of the important properties since it represents the binder's ability to be pumped through an asphalt plant, thoroughly coat the aggregate in an asphalt mixture, and be placed and compacted to form a new pavement surface (Asphalt Institute 2003).

Due to the high sensitivity of the asphalt binder to the variations in temperature, the stiffness modulus of the control and modified mixture decreases at higher temperatures. This phenomenon can be explained by the viscosity and the stiffness modulus of the asphalt binder, which decrease at higher temperatures. Therefore, the stiffness modulus of the mixture decreases as a result of the greater ease with which the aggregates slide, moreover softening the HMA specimens. When the temperature increases, the viscosity of the asphalt binder decreases thus allowing it to flow within the mix and relieve the stresses. However, the asphalt binder may lose its ability to bind the aggregates together at high temperatures. Therefore, as the temperature increases, the recoverable strain needed increases as well resulting in a lower stiffness modulus (Arabani 2011).

As another observation from Figure 4, the evolution of the stiffness modulus is almost ascending at different

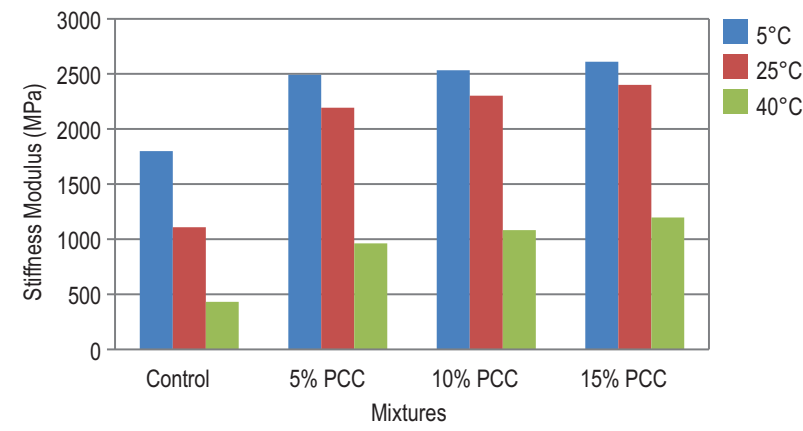

Fig. 4. Stiffness modulus test results temperatures. This means that at a certain temperature, samples with $15 \%$ PCC have the highest stiffness modulus values. Additionally, the lower sensitivity of modified mixtures to variations in temperature is also visible. Considering the influence of temperature on the mixture stiffness modulus, the results show that the stiffness modulus of PCC mixtures is at a constant value for low and intermediate temperatures. At temperature of $40^{\circ} \mathrm{C}$, the stiffness modulus for the PCC mixture significantly decreases from the previous temperatures. This could be due to the use of PCC and production of stiffer asphalt, but this characteristic does not exist in the control mixture.

\subsection{Dynamic creep test}

As shown in Figures 5, 6, and 7, the number of pulses resulting to failure for mixtures with and without PCC at temperatures 5,25 , and $40{ }^{\circ} \mathrm{C}$ are compared. It was observed that in all temperatures, mixtures including PCC have less permanent deformation. When PCC is increased, permanent deformation decreases and keeps a descending pace to $15 \%$ of PCC.

The temperature rise leads to an increase in rutting potential in control and modified asphalt samples; asphalt binder's high sensitivity to changes of temperature being the cause. With an increase in temperature, the viscosity and stiffness of asphalt binder descends and makes it softer. These factors are in agreement with Strategic Highway Research Program (SHRP) qualification for the rutting property (Kebritchi et al. 2011).

On one hand, PCC decreases the temperature sensitivity of the asphalt binder by decreasing its penetration and increasing its softening point. On the other hand, the procedure of changes in permanent deformation at any temperature follows the last model, but the level of influence of PCC in decreasing deformation is more significant in higher temperatures than in lower ones.

As shown in Figure 5, the difference of permanent deformation between control and modified mixtures is not much at a temperature of $5{ }^{\circ} \mathrm{C}$. It is believed that the first mechanism of rutting (densification; decrease of mass and increase of density) happens as the curve is passing through first and the second zone. At the temperature of $25^{\circ} \mathrm{C}$, the influence of PCC on rutting is greater, but still the first rutting mechanism takes place.

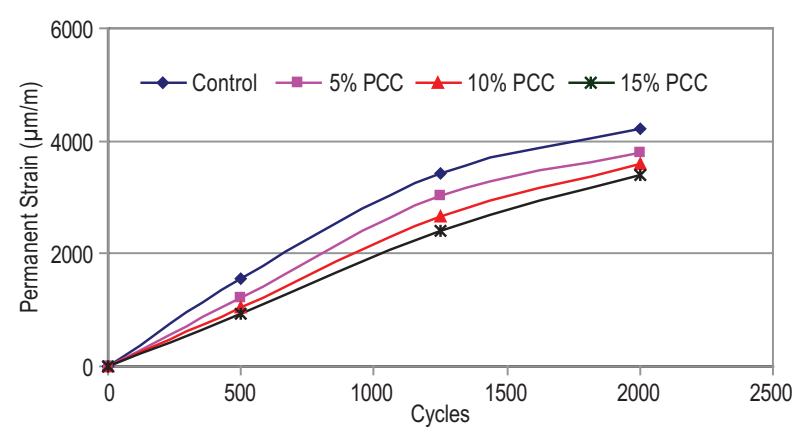

Fig. 5. Number of cycles versus permanent deformation at $5^{\circ} \mathrm{C}$ 


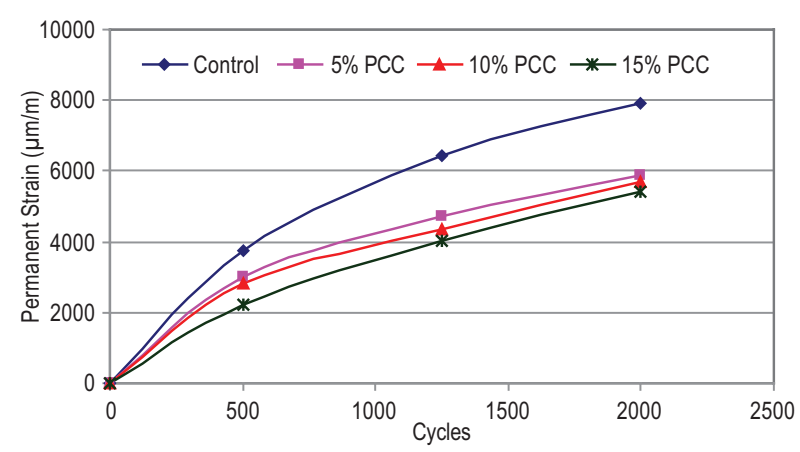

Fig. 6. Number of cycles versus permanent deformation at $25^{\circ} \mathrm{C}$

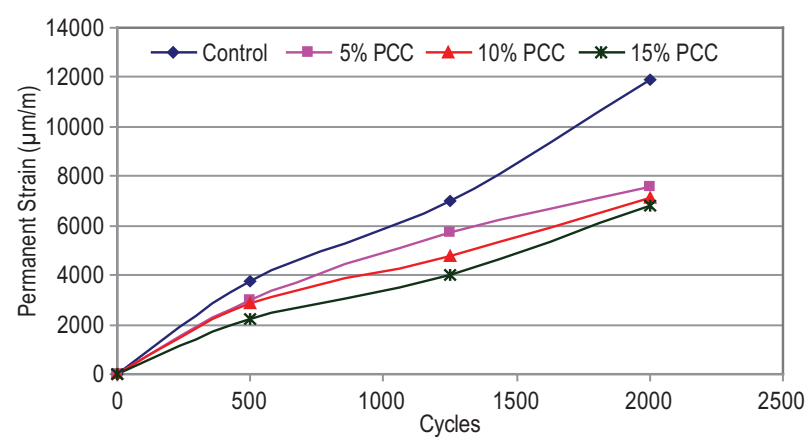

Fig. 7. Number of cycles versus permanent deformation at $40^{\circ} \mathrm{C}$

As one can conclude, mixtures with 5\% PCC have $25.7 \%$ less deformation compared to the control mixture. This amount equals to 28.2 and $31.9 \%$ for 10 and $15 \%$ of PCC usage, respectively.

The descending rate of permanent deformation is more in mixtures with 5\% PCC and when it goes up to 10 and $15 \%$, changes in deformation slows down. Therefore, as the viscosity of asphalt binder increases with PCC and also the mixing process consumes more time and energy, $5 \%$ of PCC being mixed is believed to be the optimal amount. When the temperature increases to $40^{\circ} \mathrm{C}$, one can see that in the control mixture, the second rutting mechanism (shear deformation; plastic flow with

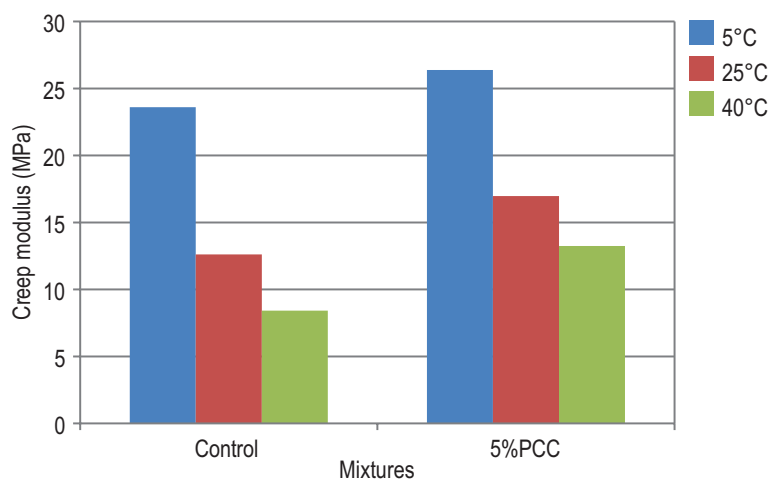

Fig. 8. Creep modulus values of the control and modified asphalt mixtures no change in the volume) occurs and the curve enters the third zone which ends in failure. However, the modified mixtures remain in the second zone, where accumulative strains occur with a smooth slope. At this temperature, permanent deformation of the mixture with 5\% PCC (to be called optimal mixture) is $36.4 \%$ less than the control mixture. As a result, one can conclude that PCC could be identified as a good asphalt binder modifier to be used in the main roads in tropical regions, where the rutting effect is known to be one of the main failures.

The creep modulus values of control and optimum mixtures are given in Figure 8. In unmodified specimens, the rate of reduction is more than the modified samples. Compared to the control mixture, there is a substantial improvement in the resistance to permanent deformation of the mixtures containing 5\% PCC as indicated by higher creep modulus at different temperatures. However, by increasing the temperature, the creep modulus of all specimens decreases. This behavior results from high sensitivity of asphalt binder to temperature in asphalt mixtures.

\section{Conclusions}

The objective of this study is to investigate the rutting characteristics of asphalt mixtures with PCC additive. The resistance to permanent deformation of mixtures was evaluated by using the dynamic creep and indirect tensile stiffness modulus tests. Based on the experimental results for the asphalt binders and the mixes, the following observations can be made:

1. The results obtained by the indirect tensile stiffness modulus and dynamic creep tests for samples showed that $5 \% \mathrm{PCC}$ is an optimal content in asphalt mixtures.

2. Asphalt mixtures with PCC have less rutting potential compared to control mixtures. This trend remains at $15 \%$ of PCC. However, asphalt mixtures with $5 \%$ PCC are identified as the optimal mixture because a decrease of deformation occurs with a bigger slope.

3. Due to the high sensitivity of the asphalt binder to the variation of temperatures, the stiffness modulus of mixtures decreases at higher temperatures. This phenomenon can be explained because the viscosity and the stiffness modulus of the asphalt binder decrease at higher temperatures, and therefore the stiffness modulus of the mixture decreases. However, PCC modified asphalt binder is less sensitive to temperature changes because adding PCC leads to an increase in stiffness of the asphalt binder.

4. Temperature increase causes the rutting potential to ascend. However, mixtures with PCC have less sensitivity to temperature changes, and an increase of permanent deformation in these mixtures is less than the control mixture. 


\section{References}

Arabani, M.; Azarhoosh, A. R. 2012. The effect of recycled concrete aggregate and steel slag on the dynamic properties of asphalt mixtures, Construction and Building $\mathrm{Ma}$ terials 35: 1-7.

http://dx.doi.org/10.1016/j.conbuildmat.2012.02.036

Arabani, M. 2011. Effect of glass cullet on the improvement of the dynamic behaviour of asphalt concrete, Construction and Building Materials 25(3): 1181-1185. http://dx.doi.org/10.1016/j.conbuildmat.2010.09.043

Asphalt Institute. 2003. Performance graded asphalt binder specification and testing. Superpave Series No. 1 (SP-1). Lexington, K.Y., USA. 69 p.

ASTM C1252-06 Standard Test Methods for Uncompacted Void Content of Fine Aggregate (as Influenced by Particle Shape, Surface Texture, and Grading). American Society for Testing and Materials (ASTM), USA, 2006. 5 p.

ASTM C127-12 Standard Test Method for Density, Relative Density (Specific Gravity), and Absorption of Coarse Aggregate. American Society for Testing and Materials (ASTM), USA, 2012. 6 p.

ASTM C128-12 Standard Test Method for Density, Relative Density (Specific Gravity), and Absorption of Fine Aggregate. American Society for Testing and Materials (ASTM), USA, 2012. 6 p.

ASTM C131-06 Standard Test Method for Resistance to Degradation of Small-Size Coarse Aggregate by Abrasion and Impact in the Los Angeles Machine. American Society for Testing and Materials (ASTM), USA, 2006. 4 p.

ASTM C88-13 Standard Test Method for Soundness of Aggregates by Use of Sodium Sulfate or Magnesium Sulfate. American Society for Testing and Materials (ASTM), USA, 2013. 5 p.

ASTM D1074-09 Standard Test Method for Compressive Strength of Bituminous Mixtures. American Society for Testing and Materials (ASTM), USA, 2009. 4 p.

ASTM D113-07 Standard Test Method for Ductility of Bituminous Materials. American Society for Testing and Materials (ASTM), USA, 2007. 4 p.

ASTM D1754/D1754M-09 Standard Test Method for Effect of Heat and Air on Asphaltic Materials (Thin-Film Oven Test). American Society for Testing and Materials (ASTM), USA, 2009. $6 \mathrm{p}$

ASTM D2042-09 Standard Test Method for Solubility of Asphalt Materials in Trichloroethylene. American Society for Testing and Materials (ASTM), USA, 2009. 3 p.

ASTM D3515-01 Standard Specification for Hot-Mixed, HotLaid Bituminous Paving Mixtures (Withdrawn 2009). American Society for Testing and Materials (ASTM), USA, 2009. $5 \mathrm{p}$

ASTM D36-76 Standard Test Method for Softening Point Of Bitumen (Ring-And-Ball Apparatus). American Society for Testing and Materials (ASTM), USA, 1976. 4 p.

ASTM D4791-10 Standard Test Method for Flat Particles, Elongated Particles, or Flat and Elongated Particles in Coarse Aggregate. American Society for Testing and Materials (ASTM), USA, 2010. 6 p.

ASTM D5-73(1978) Standard Test Method for Penetration Of Bituminous Materials. American Society for Testing and Materials (ASTM), USA, 1978. 5 p.

ASTM D854-14 Standard Test Methods for Specific Gravity of Soil Solids by Water Pycnometer. American Society for Testing and Materials (ASTM), USA, 2014. 8 p.

ASTM D92-12b Standard Test Method for Flash and Fire Points by Cleveland Open Cup Tester. American Society for Testing and Materials (ASTM), USA, 2012. $11 \mathrm{p}$.
Bahuguna, S. 2003. Permanent deformation and rate effects in asphalt concrete: constitutive modeling and numerical implementation. $\mathrm{PhD}$ dissertation. Case Western Reserve University, Cleveland, OH, USA.

Bernier, A.; Zofka, A.; Yut, I. 2012. Laboratory evaluation of rutting susceptibility of polymer-modified asphalt mixtures containing recycled pavements, Construction and Building Materials 31: 58-66.

http://dx.doi.org/10.1016/j.conbuildmat.2011.12.094

British Standards Institution (BSI). 1993. Method for determination of the indirect tensile stiffness modulus of bituminous mixtures. Draft for Development Rep. No. 213, London, UK.

Cooper, K. E.; Brown, S. F. 1989. Development of a simple apparatus for the measurement of the mechanical of asphalt mixes, in Proc. of Eurobitument Symposium, 1989, 494-498.

Goh, S. W.; You, Z. 2009. A simple stepwise method to determine and evaluate the initiation of tertiary flow for asphalt mixtures under dynamic creep test, Construction and Building Materials 23(11): 3398-3405.

http://dx.doi.org/10.1016/j.conbuildmat.2009.06.020

Gokhale, S.; Choubane, B.; Byron, T.; Tia, M. 2005. Rut initiation mechanisms in asphalt mixtures as generated under accelerated pavement testing, Journal of Transport Research Record 1940: 136-45.

http://dx.doi.org/10.3141/1940-15

Jeong, K. D.; Lee, S. J.; Kim, K. W. 2011. Laboratory evaluation of flexible pavement materials containing waste polyethylene (WPE) film, Construction and Building Materials 25(4): 1890-1894. http://dx.doi.org/10.1016/j.conbuildmat.2010.11.068

Kebritchi, A.; Jalali-Arani, A.; Roghanizad, A. A. 2011. Rheological behavior and properties of bitumen modified with polymeric coated precipitated calcium carbonate, Construction and Building Materials 25(6): 2875-2882. http://dx.doi.org/10.1016/j.conbuildmat.2010.12.043

Khodaii, A.; Mehrara, A. 2009. Evaluation of permanent deformation of unmodified and SBS modified asphalt mixtures using dynamic creep test, Construction and Building $\mathrm{Ma}$ terials 23(7): 2586-2592. http://dx.doi.org/10.1016/j.conbuildmat.2009.02.015

Kumar, S. A.; Veeraragavan, A. 2011. Dynamic mechanical characterization of asphalt concrete mixes with modified asphalt binders, Materials Science and Engineering: A 528(21): 6445-6454. http://dx.doi.org/10.1016/j.msea.2011.05.008

Laurinavičius, A.; Oginskas, R. 2006. Experimental reserch on the development of rutting in asphalt concrete pavements reinforced with geosynthetic materials, Journal of Civil Engineering and Management 12(4): 311-317.

Ozen, H. 2011. Rutting evaluation of hydrated lime and SBS modified asphalt mixtures for laboratory and field compacted samples, Construction and Building Materials 25(2): 756-765. http://dx.doi.org/10.1016/j.conbuildmat.2010.07.010

Pardhan, M. M. 1995. Permanent deformation characteristics of asphalt aggregate mixture using varied material and modeling procedure with Marshall Method. $\mathrm{PhD}$ dissertation. Civil Engineering. Montana University, Missoula, USA.

Radziszewski, P. 2007. Modified asphalt mixtures resistance to permanent deformations, Journal of Civil Engineering and Management 13(4): 307-315.

Verstraten, J. 1994. Bituminous materials with a high resistance to flow rutting. Belgium: PIARC TC8. 160 p. 
Fereidoon MOGHADAS NEJAD. He is an Associate Professor of Pavement Engineering and Director of the Pavement Engineering lab in Department of Civil Engineering at Amirkabir University of Technology, Iran. He holds a PhD degree from The University of Sydney since 1997. His research interests include numerical methods in pavement and railway engineering; computational models for asphalt and concrete pavements; pavement management systems, nondestructive testing; pavement recycling; and pavement materials testing.

Ali Reza AZARHOOSH. He is a PhD student Civil Engineering at Amirkabir University of Technology, Tehran, Iran. His research interests include the Management waste aggregates and resume them as substitute aggregate in asphalt mixtures. Azarhoosh's research focuses on asphalt pavement (containing waste aggregates) failures such as rutting, fatigue and moisture damage.

Gholam Hossein HAMEDI. He is studding his PhD degree in the Faculty of Civil \& Environment Engineering at the Amirkabir University of Technology, Tehran, Iran. His research interests are in the area of infrastructure materials. He performs research that relates fundamental material properties related to the mechanisms of damage in asphalt mixtures. Hamedi's research focuses on asphalt pavements performance, microstructure characterization of materials, and moisture damage in asphalt mixtures.

Mohammad Javad AZARHOOSH. He is from Iran. He was born in March 22nd, 1988, in Ramsar, a small city at the North of Iran. He studied Basic School and High School there. After Entry Exam of Iran Universities, in 2005, he entered Sahand University of Technology, to study in Chemical Engineering, with the Food industry major. After B.Sc. course, in 2009, he went to Tehran, to study M.Sc. in Advance Chemical Engineering, in the Amirkabir University of Technology. Currently, since 2011, he is living in Tehran, capital of Iran, and he is a PhD student of Chemical Engineering Department of Amirkabir University of Technology. His Research interest is procedures Reforming of Methan to Synthesis gas, and Optimization and Simulations of operations with Matlab. 